\title{
Pengaruh Modal Intelektual terhadap Kinerja Organisasional: Studi pada Konteks Perguruan Tinggi di Indonesia
}

\author{
Hafiez Sofyani ${ }^{1}$ \\ Fakultas Ekonomi dan Bisnis \\ Universitas Muhammadiyah \\ Yogyakarta, Indonesia
}

\author{
Aulia Khairunisa ${ }^{2}$ \\ Fakultas Ekonomi dan Bisnis \\ Universitas Muhammadiyah \\ Yogyakarta, Indonesia
}

\begin{abstract}
Surel : hafiez.sofyani@umy.ac.id
ABSTRAK

Penelitian ini menguji pengaruh modal intelektual terhadap kinerja perguruan tinggi (PT) di Indonesia. Penelitian ini dilakukan dengan pendekatan survei kuesioner. Sampel penelitian ini adalah PT di pulau Jawa, sementara responden penelitian adalah para pejabat struktural. Pengujian hubungan modal intelektual dan kinerja PT dilakukan dengan uji regeresi. Penelitian ini menemukan secara empiris bahwa modal intelektual berpengaruh positif terhadap kinerja PT. Secara rinci, ditemukan bahwa modal struktural dan relasional berpengaruh positif terhadap kinerja PT, sedangkan modal manusia dan modal sosial tidak. Dari temuan tersebut, disarankan agar upaya pengelolaan modal intelektual di PT terus ditingkatkan, khususnya dimensi modal struktural dan relasional. Hal ini mengingat dua aspek tersebut berdampak positif terhadap kinerja PT.
\end{abstract}

Kata Kunci: $\quad$ Modal Intelektual; Perguruan Tinggi; Kinerja.

The Effect of Intellectual Capital on Organizational Performance: A Study in the Context of Higher Education in Indonesia

\section{ABSTRACT}

This study examined the effect of intellectual capital on the performance of higher education institutions (HEIs) in Indonesia. This research was conducted using a questionnaire survey approach. The sample of this research was HEIs in Java island, while the research respondents are structural officials. The relationship between the intellectual capital and HEI performance was tested using the regression analysis. This study found empirically that intellectual capital has a positive effect on the performance of HEIs. In detail, it was found that structural and relational capital positively influence HEI performance whilst human and social capital do not. From these findings, it is suggested that efforts to manage intellectual capital in HEIs should continue to be improved, i.e. structural and relational capital dimensions in particular, given the positive impact these two bring.

Keywords: Intellectual Capital; Higher Education Institutions; Performance.

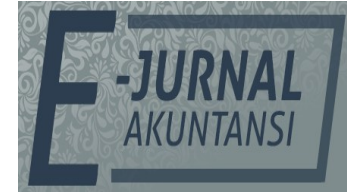

e-ISSN 2302-8556

Vol. 31 No. 7

Denpasar, Juli 2021

Hal. 1760-1770

DOI:

10.24843/EJA.2021.v31.i07.p12

PENGUTIPAN:

Sofyani, H., \& Khairunisa, A.

(2021). Pengaruh Modal Intelektual terhadap Kinerja

Organisasional: Studi pada Konteks Perguruan Tinggi di Indonesia. E-Jurnal Akuntansi, 31(7), 1760-1770

RIWAYAT ARTIKEL: Artikel Masuk: 17 Mei 2021 Artikel Diterima: 17 Juli 2021

Artikel dapat diakses : https://ojs.unud.ac.id/index.php/Akuntansi/index 


\section{PENDAHULUAN}

Modal intelektual merupakan faktor penting yang dapat mendorong dan menciptakan nilai positif bagi entitas (Xu \& Liu, 2020a). Oleh karenanya, organisasi harus fokus pada penciptaan modal intelektual. Modal intelektual merupakan penggerak nilai yang mengarah pada upaya pencapaian kinerja perusahaan yang lebih baik (Clarke et al., 2011). Secundo et al. (2020) menyatakan bahwa modal intelektual memiliki peran penting terhadap keberlanjutan tujuan entitas di masa depan. Ilmu pengetahuan dan teknologi yang selalu berkembang sangat memengaruhi organisasi dalam menggunakan sumber daya lain dengan efisien dan ekonomis yang dapat menjadi keunggulan bersaing (Thaib, 2013).

Sebuah organisasi tidak dapat mewujudkan tujuannya jika sumber daya strategisnya terutama pada modal intelektual dan aset pengetahuan tidak dikelola dengan baik (Ulum, 2013). Beberapa penelitian terkini masih menemukan bahwa peran modal intelektual terhadap kinerja peruashaan adalah sangat krusial ( $\mathrm{Xu} \&$ Li, 2020b) dan (Hoang et al., 2020). Sebagai contoh, Tjahjadi et al. (2019) menemukan bahwa modal intelektual berperan penting sebagai pemediasi hubungan sistem manajemen kinerja dan kinerja organisasional suatu entitas. Karenanya, mereka menyarankan bahwa selain memperhatikan aspek kebijakan manajemen kinerja, manajer juga harus memastikan modal intelektual dikelola secara baik agar dapat secara optimal meningkatkan kinerja organisai.

Sejauh ini, studi terkait peran modal intelektual lebih banyak dibahas pada lembaga berorientasi profit, yakni perusahaan, dari pada lembaga tidak berorientasi profit seperti pemerintahan, rumah sakti, dan PT. Kondisi ini memunculkan adanya celah penelitian. Salah satu studi terkait peran modal intelektual di PT dilakukan oleh Kong et al. (2010) mereka menemukan bahwa modal intelektual dapat meningkatkan kinerja PT di Italia. Studi Kong et al. (2010) dilakukan pada konteks negara maju eropa dan dilakukan dengan pendekatan exploratori pada satu kasus karenanya, studi di negara berkembang, seperti Indonesia yang tata kelola PT-nya berbeda, perlu dilakukan. Selain itu, studi dengan desain lain yang memungkinkan penarikan kesimpulan yang lebih luas (validitas eksternal), sebagaimana penggunaan metode survei, perlu dilakukan untuk memperkaya literatur terkait peran modal intelektual di konteks organisasi PT.

Di sisi lain, temuan Kong et al. (2010) menegaskan bahwa modal intelektual ini penting diterapkan tidak hanya di organisasi bisnis tetapi juga PT terlebih, PT berperan penting dalam mengembangkan dan menyebarkan ilmu pengetahuan dan teknologi untuk kesejahteraan rakyat di suatu negara secara luas (Canibano dan Sanchez, 2009) di sisi lain, fokus pengelolaan modal intelektual sangat relevan bagi PT di Indonesia karena mayoritas PT Indonesia masih mempunyai kinerja dan kualitas yang rendah dibandingkan dengan PT lain di ASEAN (Pratolo et al., 2020).

Hingga hari ini studi mengenai modal intelektual PT di Indonesia sudah beberapa kali dilakukan. Namun, studi sebelumnya hanya fokus kepada determinan dan tingkat pengungkapan modal intelektual Herawati et al., (2020), Gobel et al., (2020), Aulia et al., (2019) dan Ulum et al., (2019), pengaruh pengungkapan modal intelektual terhadap minat calon mahasiswa baru Ulum et al., (2019) dan daya saing PT Rahayuningtyas \& Triana, (2017), dan framework 
modal intelektual di PT Indonesia berbasis borang akreditasi 4.0 (Ulum, 2019). Sementara itu, studi terkait peran modal intelektual terhadap kinerja PT yang diuji secara simultan dan perdemensi masih sulit ditemukan dan karenanya menjadi celah penelitian. Untuk menutupi celah tersebut penelitian ini diinisiasi.

Secara khusus, penelitian ini bertujuan untuk menguji pengaruh modal intelektual yang terdiri dari dimensi modal manusia, struktural, relasional, dan sosial terhadap kinerja PT di Indonesia. Hasil studi ini memberikan sumbangsih kepada literatur, khususnya terkait peran modal intelektual terhadap kinerja pada konteks organisasi PT di negara berkembang yang masih mendapat perhatian minim oleh akademisi. Di samping itu, hasil studi ini diharapkan menjadi masukan bagi manajemen PT dan pembuat kebijakan, yakni kementrian Pendidikan dan Budaya, untuk merumuskan kebijakan terkait pengelolaan modal intelektual.

Kajian peran modal intelektual terhadap kinerja organisasi sangat relevan dengan teori berbasis sumber daya (Resource-based view theory) yang dipromosikan oleh (Barney 1991). Barney (1991) berpendapat bahwa organisasi dapat mencapai keunggulan kompetitif jika mereka memiliki sumber daya yang memenuhi empat kriteria: berharga, langka, sulit untuk ditiru, dan tidak memiliki pengganti yang setara. Keempat kriteria tersebut berarti bahwa sumber daya oragnisasi yang dimiliki harus diterapkan atau digunakan secara efektif. Dari kaca mata teori berbasis sumber adya, modal intelektual dapat diidentifikasi sebagai sumber daya yang melibatkan manusia (modal manusia) dan organisasional (modal struktural, relasional, dan sosial) (Barney, 1991). Efektivitas pengelolaan modal intelektual diharapkan menjadi pemicu keunggulana kompetitif organsisasi yang dapat dilihat dari kinerja yang diraih.

Selanjutnya, Secundo et al (2010) menyebutkan bahwa keberadaan modal intelektual dapat memicu meningkatnya daya saing perguruan tinggi karena dapat mempunyai fokus untuk mengelola sumber daya yang ada sehingga mampu bertahan pada lingkungan yang cepat berubah. Dalam organisasi, modal intelektual ini dapat menjadi pengaruh penting dalam aktivitasnya. Subramaniam \& Youndt (2005) menyebutkan bahwa aset pengetahuan khusus yang terdapat pada modal intelektual dapat membuat organisasi memanfaatkan potensi sumber daya manusia, struktural, budaya, dan jaringan kepada pihak eksternal dan selanjutnya mampu mencapai peningkatan kinerja. Beberapa riset pada konteks perusahaan telah menemukan bahwa modal intelektual dapat meningkatkan kinerja perusahaan. Pratama et al. (2019) menemukan bahwa modal intelektual dapat menghasilkan kinerja keuangan yang lebih tinggi bagi perusahaanperusahaan di ASEAN. Temuan serupa dijabarkan oleh Sirojudin \& Nazaruddin (2014) dan Baroroh (2014) bahwa modal intelektual berpengaruh positif terhadap kienrja perusahaan di masa mendatang. Namun, studi yang mnguji secara empiris pern modal intelektual pada konteks PT di Indonesia masih sulit ditemukan. Menggunakan logika yang dipaparkan sebelumnya, hal serupa juga mungkin berlaku pada konteks perguruan tinggi bahwa modal intelektual harus dikelola dengan baik agar kinerja perguruan tinggi meningkat. Dari argument yang dipaparkan, maka hipotesis penelitian ini adalah sebagai berikut.

$\mathrm{H}_{1}$ : Modal intelektual berpengaruh positif terhadap kinerja perguruan tinggi. 


\section{METODE PENELITIAN}

Penelitian ini menggunakan desain penelitian survei. Teknik pengambilan sampel yang digunakan adalah convenience sampling yaitu pemilihan sampel perguruan tinggi dengan yang lebih mudah untuk di akses sesuai dengan keinginan peneliti dan mampu menyediakan informasi tersebut (Zikmund, Carr, \& Griffin, 2013). Teknik pengambilan unit sampel yang digunakan adalah purposive sampling yaitu pengambilan sampel dengan menentukan kriteria-kriteria tertentu (Smith, 2019). Unit sampel dipilih dengan kriteria yaitu merupakan pejabat stuktural yang mengetahui tentang modal intelektual dan kinerja PT. Untuk mengetahui pejabat Dekan, Wakil Dekan, Kaprodi, Sekretasis Prodi informasi tersebut diperoleh dari website perguruan tinggi yang dimaksud. Perlu diketahui bahwa studi ini memiliki empat prediktor (Modal manusia, struktural, relasional, dan sosial). Mengacu pada analisis power sebagaimana disarankan Memon et al. (2020) dalam menentukan kriteria jumlah sampel, jika terdapat empat predictor variabel dependen, maka sampel minimal dari studi itu adalah 50. Pada studi ini total kuesioner disebar ditujukan kepada 100 PT, namun yang kembali adalah 83 . Setelah 12 responden yang tidak sesuai dengan kriteria dikeluarkan, total data yang dapat diolah adalah 71 dari 71 PT. Dengan demikian, meskipun jumlah sampel studi ini sedikit, tetapi itu telah memenuhi kriteria minimal sebagaimana saran Momen et al. (2020).

Pada penelitian ini, kinerja PT diukur menggunakan instrumen borang akreditasi PT yang berlaku di Indonesia, sesuai konteks riset. Sedangkan variabel modal intelektual terdiri dari dimensi modal manusia, modal struktural, modal relasional, dan modal social. Modal intelektual ini diukur dengan merujuk kepada penelitian Asiaei, Jusoh dan Bontis (2018). Secara rinci, indikator kinerja PT mencakup pendidikan sesuai kurikulum baru KKNI, efektivitas perkualiahan, pembimbingan tugas akhir mahasiswa selesai sesuai jadwal, publikasi di jurnal terakreditasi SINTA 2, publikasi di jurnal internasional bereputasi, kinerja pengabdian masyarakat, efektivitas pelayanan kepada semua civitas akademika kampus, kecepatan pelayanan kepada semua civitas akademika kampus, dan kinerja kampus sesuai indikator kinerja yang ditetapkan. Selanjutnya, indikator dimensi modal manusia meliputi kapabilitas kepemimpinan pihak manajemen kampus, kontribusi manajemen kampus terhadap kinerja, keahlian manajemen kampus dalam menjalankan jabatan, dan keahlian pegawai kampus dalam menjalankan tugas. Indikator dimensi modal struktural adalah investasi untuk inovasi, sistem informasi, kreativitas ide, pengembangan teknologi informasi, dan peduli aspirasi para pemangku kepentingan. Selanjutnya, indikator dimensi modal relasional mencakup orientasi pada kebutuhan pemangku kepentingan, interaksi dengan organisasi lain dari berbagai wilayah, dan menjaga hubungan baik dengan semua pemangku kepentingan. Sementara indikator dimensi modal sosial meliputi intensitas waktu untuk berinteraksi dengan pemangku kepentingan, kolaborasi antar unit dalam mencapai kinerja, kolaborasi antar unit dalam menyelesaikan masalah, dan budaya berbagi informasi antar unit.

Sebelum dilakukan survei lapangan, dilakukan validasi ahli terhadap kuesioner. Para ahli berasal dari beberapa universitas di Yogyakarta yang berstatus doktor. Validasi bertujuan untuk mendapatkan input untuk perbaikan kuesioner. Setelah mendapatkan masukan, kuesioner diperbaiki dari segi panjang 
kalimat, penggunaan kata dan tanda baca, serta kata-kata yang berpotensi ambigu. Pengukuran semua variabel menggunakan skala lima poin tipe Likert, peringkat dari 1 = "Sangat tidak setuju" hingga 5 = "Sangat setuju" digunakan untuk semua pertanyaan.

Studi ini dilakukan pada masa pandemi Covid-19, mayoritas kuesioner disebarkan secara daring. Namun, untuk beberapa perguruan tinggi yang ada di Yogyakarta, penyebaran kuesioner dilakukan secara langsung kepada responden dengan mematuhi protokol kesehatan. Kuesioner yang disebarkan melalui daring responnya sangat rendah. Jumlah responden dan sampel yang berpartisipasi pada penelitian ini juga relatif sedikit. Namun, setidaknya jumlah sampel telah memenuhi syarat untuk uji regresi jika mengacu pada analisis power (lihat: Memon et al., 2020) dan jumlah sampel minimal, yakni 30 (Alwi, 2015). Selanjutnya, data dianalisis dengan menggunakan dua teknik, yakni analisis statistik deskriptif dan uji pengaruh modal intelektual terhadap kinerja PT. Keduanya dilakukan dengan menggunakan software SPSS.

\section{HASIL DAN PEMBAHASAN}

Pada Tabel 1, disajikan analisis statistik deskriptif variabel secara keseluruhan, sementara Tabel 2, menyajikan statistic deskriptif variabel per-indikator. Dari Tabel 1, dapat disimak bahwa rata-rata modal intelektual perguruan tinggi sampel cukup baik, yakni lebih dari skala 4 namun rerata kinerja masih kurang optimal, yakni 3,77.

Tabel 1. Hasil Analisis Statistik Deskriptif Secara Keseluruhan

\begin{tabular}{ccccc}
\hline Variabel & Minimum & Maksimum & Rerata & Deviasi standar \\
\hline Modal Intelektual & 2,94 & 5,00 & 4,12 & 0,46 \\
- Modal Manusia & 3,00 & 5,00 & 4,01 & 0,61 \\
- $\quad$ Modal Struktural & 2,80 & 5,00 & 4,01 & 0,57 \\
- Modal Relasional & 3,00 & 5,00 & 4,32 & 0,52 \\
- Modal Sosial & 2,25 & 5,00 & 4,12 & 0,65 \\
Kinerja Perguruan Tinggi & 2,88 & 4,88 & 3,77 & 0,72 \\
N=71 & & & &
\end{tabular}

$\mathrm{N}=71$

Sumber: Data Penelitian, 2021

Tabel 2, menyatakan indikator kinerja PT yang memiliki skor kurang optimal atau dari skala 4 adalah pendidikan sesuai kurikulum baru KKNI (KPT1), efektivitas perkualiahan (KPT2), publikasi di jurnal terakreditasi SINTA 2 (KPT4), publikasi di jurnal internasional bereputasi (KPT5), dan kinerja pengabdian masyarakat (KPT6). Padahal, Indikator dimaksud semuanya adalah Indikator utama Tri Dharma (Tiga Kewajiban Utama) PT, yakni pengajaran, riset dan publikasi, dan pengabdian kepada masyarakat. Temuan ini sangat krusial untuk ditindaklanjuti karena mengindikasikan secara rerata tugas utama dari keberadaan PT masih belum optimal.

Indikator modal intelektual yang dipersepsikan responden masih belum optimal adalah berasal dari modal manusia, yakni keahlian pegawai kampus dalam menjalankan tugas (MM4), dan modal structural, yani investasi untuk inovasi (MS1), dan kreativitas ide (MS3). Temuan ini juga penting untuk ditindaklanjuti oleh PT mengingat di era revolusi industri 4.0 ini PT dituntut untuk terus berinovasi dan kreatif dalam menghadapi tantangan zaman. Minim inovasi 
dan kreativitas akan sangat mungkin menjadikan PT tertinggal bahkan dibubarkan karena lemah dalam hal day saing.

Tabel 2. Hasil Analisis Statistik Deskriptif Per-Indikator

\begin{tabular}{|c|c|c|c|c|c|}
\hline \multicolumn{2}{|c|}{ Variabel/Indikator } & Min. & Mak. & Rerata & DS \\
\hline \multicolumn{6}{|c|}{ Kinerja PT } \\
\hline KPT1 & Pendidikan sesuai kurikulum baru KKNI & 2,00 & 5,00 & 3,99 & 0,64 \\
\hline КРТ2 & Efektivitas perkualiahan & 2,00 & 5,00 & 3,80 & 0,73 \\
\hline КРT3 & $\begin{array}{l}\text { Pembimbingan tugas akhir mahasiswa } \\
\text { selesai sesuai jadwal }\end{array}$ & 3,00 & 5,00 & 4,06 & 0,58 \\
\hline KPT4 & Publikasi di jurnal terakreditasi SINTA 2 & 1,00 & 5,00 & 3,39 & 0,90 \\
\hline KPT5 & $\begin{array}{l}\text { Publikasi di jurnal internasional } \\
\text { bereputasi }\end{array}$ & 1,00 & 5,00 & 2,99 & 0,99 \\
\hline КРT6 & Kinerja pengabdian masyarakat & 2,00 & 5,00 & 3,82 & 0,78 \\
\hline KРT7 & $\begin{array}{l}\text { Efektivitas pelayanan kepada semua } \\
\text { civitas akademika kampus }\end{array}$ & 3,00 & 5,00 & 4,08 & 0,60 \\
\hline КРТ8 & $\begin{array}{l}\text { Kecepatan pelayanan kepada semua } \\
\text { civitas akademika kampus }\end{array}$ & 2,00 & 5,00 & 4,03 & 0,68 \\
\hline КРТ9 & $\begin{array}{l}\text { Kinerja kampus sesuai indikator kinerja } \\
\text { yang ditetapkan }\end{array}$ & 3,00 & 5,00 & 4,07 & 0,52 \\
\hline \multicolumn{6}{|c|}{ Modal Manusia } \\
\hline MM1 & $\begin{array}{l}\text { Kapabilitas kepemimpinan pihak } \\
\text { manajemen }\end{array}$ & 3,00 & 5,00 & 4,10 & 0,64 \\
\hline MM2 & Kontribusi manajemen terhadap kinerja & 2,00 & 5,00 & 4,13 & 0,77 \\
\hline MM3 & Keahlian manajemen dalam menjabat & 2,00 & 5,00 & 4,03 & 0,74 \\
\hline MM4 & $\begin{array}{l}\text { Keahlian pegawai kampus dalam } \\
\text { menjalankan tugas }\end{array}$ & 2,00 & 5,00 & 3,93 & 0,70 \\
\hline \multicolumn{6}{|c|}{ Modal Struktural } \\
\hline MS1 & Investasi untuk inovasi, & 1,00 & 5,00 & 3,85 & 0,91 \\
\hline MS2 & Sistem informasi, & 3,00 & 5,00 & 4,15 & 0,75 \\
\hline MS3 & Kreativitas ide, & 2,00 & 5,00 & 3,76 & 0,77 \\
\hline MS4 & Pengembangan teknologi informasi & 3,00 & 5,00 & 4,41 & 0,62 \\
\hline MS5 & $\begin{array}{l}\text { Peduli aspirasi para pemangku } \\
\text { kepentingan }\end{array}$ & 2,00 & 5,00 & 4,06 & 0,63 \\
\hline \multicolumn{6}{|c|}{ Modal Relasional } \\
\hline MR1 & $\begin{array}{l}\text { Orientasi pada kebutuhan pemangku } \\
\text { kepentingan }\end{array}$ & 3,00 & 5,00 & 4,20 & 0,62 \\
\hline MR2 & $\begin{array}{l}\text { Interaksi dengan organisasi lain dari } \\
\text { berbagai wilayah }\end{array}$ & 3,00 & 5,00 & 4,35 & 0,59 \\
\hline MR3 & $\begin{array}{l}\text { Menjaga hubungan baik dengan semua } \\
\text { pemangku kepentingan }\end{array}$ & 3,00 & 5,00 & 4,41 & 0,58 \\
\hline \multicolumn{6}{|c|}{ Modal Sosial } \\
\hline MSO1 & $\begin{array}{l}\text { Intensitas berinteraksi dengan pemangku } \\
\text { kepentingan }\end{array}$ & 3,00 & 5,00 & 4,24 & 0,60 \\
\hline $\mathrm{MSO} 2$ & $\begin{array}{l}\text { Kolaborasi antar unit dalam mencapai } \\
\text { kinerj }\end{array}$ & 2,00 & 5,00 & 4,17 & 0,77 \\
\hline MSO3 & $\begin{array}{l}\text { Kolaborasi antar unit dalam } \\
\text { menyelesaikan masalah }\end{array}$ & 2,00 & 5,00 & 4,06 & 0,79 \\
\hline $\begin{array}{l}\mathrm{MSO} 4 \\
\mathrm{~N}=71\end{array}$ & Budaya berbagi informasi antar unit. & 2,00 & 5,00 & 4,01 & 0,80 \\
\hline
\end{tabular}


Sebelum uji hipotesis, terlebih dahulu dilakukan uji reliabilitas dan validitas data serta uji asumsi klasik dilakukan.

Tabel 3. Hasil Uji Reliabilitas Data

\begin{tabular}{lcc}
\hline Variabel & Cronbach's alpha & Jumlah item \\
\hline Modal intelektual & 0,94 & 16 \\
Kinerja perguruan tinggi & 0,785 & 9 \\
\hline
\end{tabular}

Sumber: Data Penelitian, 2021

Tabel 3, menyatakan skor Cronbach's Alpha variabel Modal Intelektual (MI) adalah 0,940, sementara untuk variabel Kinerja Perguruan Tinggi adalah 0,785. Dengan demikian dua variabel tersebut reliabel karena memenuhi rule of thumb yang disyaratkan, yakni lebih dari 0,6. Selanjutnya dilakukan pengecekan validitas item/indikator kuesioner. Butir pertanyaan dikatakan valid apabila memiliki faktor loading lebih dari 0,5. Pada variabel kinerja perguruan tinggi, KPT3 tidak memenuhi rule of thumb karena skor faktor loading-nya 0,410 karenanya, KPT3 dieliminasi pada uji asumsi klasik dan uji hipotesis. Sedangkan semua butir-butir pertanyaan variabel modal intelektual mempunyai faktor loading lebih dari 0,5. Dengan demikian, semua butir pertanyaan pada penelitian ini, kecuali KPT3, dinyatakan valid yang disajikan dalam Tabel 4 .

Tabel 4. Hasil Uji Validitas

\begin{tabular}{lclc}
\hline Indikator Modal intelektual & Loading & $\begin{array}{l}\text { Indikator kinerja perguruan } \\
\text { tinggi }\end{array}$ & Loading \\
\hline MM1 & 0,687 & KPT1 & 0,509 \\
MM2 & 0,802 & KPT2 & 0,543 \\
MM3 & 0,778 & KPT3* & $0,41^{*}$ \\
MM4 & 0,702 & KPT4 & 0,662 \\
MS1 & 0,564 & KPT5 & 0,509 \\
MS2 & 0,672 & KPT6 & 0,708 \\
MS3 & 0,744 & KPT7 & 0,739 \\
MS4 & 0,637 & KPT8 & 0,624 \\
MS5 & 0,796 & KPT9 & 0,737 \\
MR1 & 0,796 & & \\
MR2 & 0,616 & & \\
MR3 & 0,712 & & \\
MSO1 & 0,769 & & \\
MSO2 & 0,801 & & \\
MSO3 & 0,771 & & \\
MSO4 & 0,837 & & \\
${ }^{\text {dieliminasi }}$ & & & \\
Sumber: Data Penelitian, 2021 & & &
\end{tabular}

Setelah uji reliabilitas dan validitas data selesai, dilakukan uji asumsi klasik. Hasil uji menunjukkan bahwa data penelitian ini telah memenuhi syarat dimana data ditemukan bersifat normal, tidak mengalami autokorelasi, multikolinearitas, dan heteroskidastisitas. Dengan demikian, data riset ini memenuhi syarat untuk digunakan dalam pengujian hipotesis.

Pada Tabel 5, dapat dilihat bahwa variabel modal intelektual memiliki arah yang positif yaitu 0,338 dengan nilai signifikansi 0,000 (alpha $<0,05$ ). Artinya, modal intelektual berpengaruh postif signifikan terhadap kinerja PT. Maka dapat disimpulkan hipotesis penelitian ini Diterima. Hasil ini mengonfirmasi premis teoris berbasis sumber daya oleh Barney (1991) bahwa sumber daya yang dikelola 
secara efektif akan dapat meningkatkan keunggulan kompetitif organisasi, yang indikatornya adalah kinerja organisasional. Selain itu, secara empiris, temuan studi ini mendukung banyak riset terdahulu bahwa modal intelektual memiliki peran penting dalam meningkatkan kinerja organisasi (lihat: Pratama et al., 2019; Sirojudin \& Nazaruddin, 2014; Baroroh, 2014). Namun demikian, hasil ini memberikan kontribusi literatur karena pengujian modal intelektual dilakukan pada konteks organisasi nirlaba, yakni PT, sementara mayoritas studi terdahulu dilakukan pada konteks organisasi laba yakni perusahaan.

Tabel 5. Hasil Uji Hipotesis (Regresi)

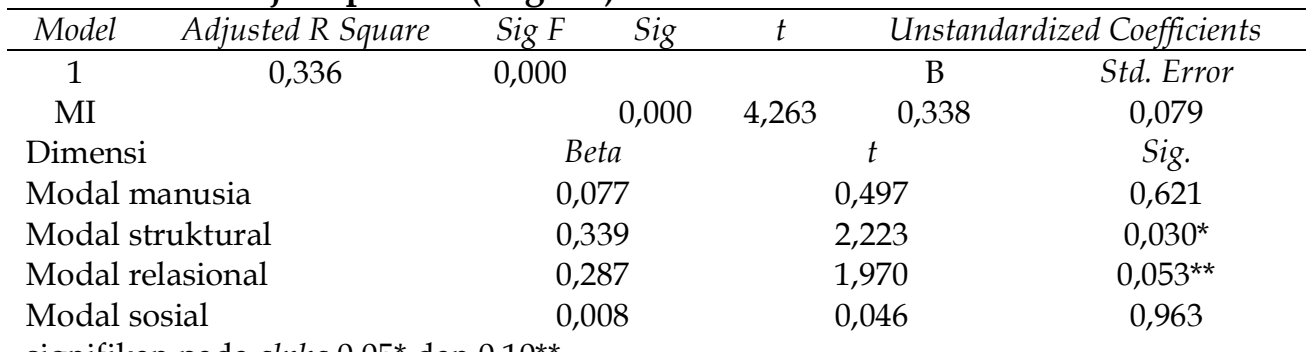

signifikan pada alpha $0,05^{*}$ dan $0,10^{* *}$

Sumber: Data Penelitian, 2021

Selanjutnya, pada studi ini dilakukan pengujian pengaruh modal intelektual per-dimensi terhadap kinerja PT untuk menemukan dimensi mana yang berkontibursi terhadap kinejra PT disajikan pada Tabel 5. Dari hasil uji, ditemukan bahwa modal struktural dan relasional berpengaruh signifikan terhadap kinerja PT, sementara modal manusia dan sosial tidak berpengaruh. Secara detil, dimensi modal struktural berkaitan dengan inovasi, teknologi, sistem informasi, dan aspirasi pemangku kepentingan. Sementara dimensi relasional berkaitan dengan kerjasama dan koordinasi PT dengan pemangku kepentingan eksternal dan organisasi lain di luar PT. Hasil ini sejalan dengan Pratolo et al. (2020) yang menemukan adanya inovasi sistem anggaran berbasis kinerja telah mampu meningkatkan kinerja PT. Mereka menemukan bahwa anggaran berbasis kinejra yang disertai dengan sistem reward dan partisipasi dalam perencanaan dan pengelolaan, memicu keterbutkaan informasi dan kejelasan sasaran, sehingga manajemen di semua level di PT dapat mengontrol realisasi target kinerja mereka. Selain itu, Sofyani dan Nazaruddin (2019) dan Thajadi et al. (2019) menemukan adanya sistem pengukuran kinerja yang efektif, sebagai bagian dari modal struktural PT, mampu meningkatkan motivasi dosen untuk meningkatkan kinerja dan selanjutnya meningkatkan kinerja PT.

Di sisi lain, dimensi modal relasional yang berkaitan dengan hubungan PT dengan organisasi lain juga merupakan faktor penting penentu kinerja PT. Sebagai contoh, relasi dengan industri dapat memicu peningkatakan kinerja dengan cara menjalin kerja sama program magang dan praktik kerja lapangan (PKL) para mahasiswa, kerjasama penelitian, dan pengabdian masyarakat para dosen. Aspekaspek tersebut merupakan indikator kinerja utama PT dalam Tri Dharma. Karenanya, semakin baik dan banyak relasi PT dengan pihak penting di luar, semakin mampu PT meningkatkan kinerja mereka dari poin-poin indikator yang disebutkan tadi. 
Selanjutnya, tidak terdukungnnya modal manusia dan sosial sebagai determinan kinerja PT bisa jadi karena di lapangan ditemukan bahwa banyak PT yang tidak mengembangkan modal struktural dan relasional secara baik, sebagai contoh sistem pengukuran kinerja, angaran berbasis kinerja, dan pola tata kelola yang baik. Akhirnya, meskipun kompetensi dosen serta kerjasama internal yang dilakukan banyak kampus relatif sama, kinerja PT nyatanya tetap beragam. Temuan ini menegaskan bahwa aspek modal intelektual yang penting mendapatkan perhatian saat ini karena menjadi pemicu yang dapat menjadi pembeda kinerja PT adalah modal struktural dan relasional.

\section{SIMPULAN}

Riset ini menemukan bahwa modal intelektual berpengaruh positif terhadap kinerja PT. Secara detail, modal struktural dan realsional menjadi faktor kritis penentu kinerja PT, sementara modal manusia dan sosial tidak. Dari temuan ini, penting bagi manajemen PT untuk terus meningkatkan pengelolaan modal intelektual khususnya pada dimensi modal struktural dan relasional agar dapat memberikan nilai tambah bagi PT. Studi ini memberikan sumbangsih kepada literatur tentang kajian peran modal intelektual pada konteks PT yang masih jarang dilakukan.

Penelitian ini tentu memiliki keterbatasan yang menyertai. Pertama, studi ini hanya dilakukan dengan melibatkan sampel PT di pulau jawa dengan jumlah yang sangat terbatas. Karenanya, validitas eksternal atau kemampuan generalisasi studi ini tidak cukup kuat. Pembaca disarankan untuk berhati-hati dalam membaca hasil studi ini. Ke depan, studi sejenis penting dilakukan di daerah lain untuk mengonfirmasi, membantah atau mengembangkan studi ini. Selanjutnya, studi ini hanya didasarkan pada metode survey. Sehingga bagaimana secara detil modal intelektual mammpun berkontribusi terhadap kinerja PT sulit dijabarkan, khususnya dari perspektif responden. Untuk menutupi keterbatsan ini, maka pada penelitian serupa di masa mendatang, pendekatan kualitatif penting untuk diadopsi. Terakhir, penelitian ini tidak menganalisis modal intelektual menggunakan pendekatan second-order, padahal variabel ini memiliki beberapa dimensi. Karenanya, bagaimana masing-masing dimensi berkontribusi dalam membentuk konstruk modal intelektual tidak terjabarkan. Oleh karena itu, isu ini perlu ditindaklanjuti dengan menggunakan teknik analisis yang berbeda, yakni dengan menggunakan structural equation modeling (SEM).

\section{REFERENSI}

Alwi, I. (2015). Kriteria empirik dalam menentukan ukuran sampel pada pengujian hipotesis statistika dan analisis butir. Formatif: Jurnal Ilmiah Pendidikan MIPA, 2(2), 140-148. http://dx.doi.org/10.30998/formatif.v2i2.95

Asiaei, K., Jusoh, R., \& Bontis, N. (2018). Intellectual capital and performance measurement systems in Iran. Journal of Intellectual Capital, 19(2), 294-320. https://doi.org/10.1108/JIC-11-2016-0125

Aulia, D., Ulum, I., \& Wahyuni, E. D. (2019). Pengaruh Ukuran, Kompleksitas, Program Internasional, dan Status Akreditasi Terhadap Pengungkapan Intellectual Capital Pada Universitas Muhammadiyah Di Indonesia. Jurnal 
$\begin{array}{llll}\text { Akademi } & \text { Akuntansi }\end{array}$ https://doi.org/10.22219/jaa.v2i2.10152

Azis, S. N., Pagalung, G., \& Habbe, A. H. (2020). Pengungkapan Modal Intelektual Dan Keuangan Dalam Kapitalisasi Pasar Dengan Siklus Hidup Industri Sebagai Pemoderasi. Jurnal Akuntansi dan Keuangan Indonesia, 16(1), 61-82. http://dx.doi.org/10.21002/jaki.2019.04

Barney, J. (1991). Firm resources and sustained competitive advantage. Journal of management, 17(1), 99-120. https:/ / doi.org/10.1177/014920639101700108

Baroroh, N. (2013). Analisis pengaruh modal intelektual terhadap kinerja keuangan perusahaan manufaktur di Indonesia. Jurnal Dinamika Akuntansi, 5(2), 172-182. https:// doi.org/10.15294/jda.v5i2.2997

Canibano, L., \& Sánchez, M. P. (2009). Intangibles in universities: current challenges for measuring and reporting. Journal of Human Resource Costing $\mathcal{E}$ Accounting, 13(2), 93-104. https://doi.org/10.1108/14013380910968610

Clarke, M., Seng, D., \& Whiting, R. H. (2011). Intellectual capital and firm performance in Australia. Journal of intellectual capital, 12(4), 505-530. https://doi.org/10.1108/14691931111181706

Gobel, I. C., Juanda, A., Ulum, I., \& Mudrifah, M. (2020). Determinants of Intellectual Capital Disclosure in Non-Vocational Higher Education in Indonesia. Journal of Accounting and Investment, 21(2), 362-382. https://doi.org/10.18196/jai.2102154

Helmiatin, H. (2015). Optimalisasi Peran Modal Intelektual Terhadap Kinerja Karyawan. Etikonomi, 14(1), 51-68. https://doi.org/10.15408/etk.v14i1.2263

Herawati, L. I., Ulum, I., \& Juanda, A. (2020). Pengungkapan Modal Intelektual Perguruan Tinggi Vokasi di Indonesia Berdasarkan Instrumen Akreditasi Program Studi (IAPS) 4.0. EKUITAS (Jurnal Ekonomi dan Keuangan), 4(1), 107-121. https:// doi.org/10.24034/j25485024.y2020.v4.i1.4428

Hoang, H. T., Nguyen, H. T. H., Vu, N. H., Le, A. H., \& Quach, H. H. (2020). Intellectual capital and firm performance in Vietnam 20122016. International Journal of Learning and Intellectual Capital, 17(1), 27-46. https://doi.org/10.1504/IJLIC.2020.105325

Kong, E., Secundo, G., Margherita, A., Elia, G., \& Passiante, G. (2010). Intangible assets in higher education and research: mission, performance or both?. Journal of intellectual capital, 11(2), 140-157. https:/ / doi.org/10.1108/14691931011039651

Memon, M., Ting, H., Cheah, J., Ramayah, T., Chuah, F., \& Cham, T. (2020). Sample size for survey research: review and recommendations. Journal of Applied Structural Equation Modelling, 4(2), 1-20. https://jasemjournal.com/wpcontent/uploads/2020/08/Memon-et-al_JASEM_-

Editorial_V4_Iss2_June2020.pdf

Pratama, B. C., Wibowo, H., \& Innayah, M. N. (2019). Intellectual Capital and Firm Performance in ASEAN: The Role of Research and Development. Journal of Accounting and Investment, 20(3), 236-250. https://doi.org/10.18196/jai.2003126

Pratolo, S., Sofyani, H., \& Anwar, M. (2020). Performance-based budgeting implementation in higher education institutions: Determinants and impact 
on quality. Cogent Business \& Management, 7(1), 1786315. https://doi.org/10.1080/23311975.2020.1786315

Rahayuningtyas, P. A., \& Triana, E. (2017). Modal Intelektual dan Daya Saing Perguruan Tinggi di Indonesia. Jurnal Akuntansi dan Investasi, 18(2), 153162. https:// doi.org/10.18196/180279

Secundo, G., Ndou, V., Del Vecchio, P., \& De Pascale, G. (2020). Sustainable development, intellectual capital and technology policies: A structured literature review and future research agenda. Technological Forecasting and Social Change, 153, 119917. https:/ / doi.org/10.1016/j.techfore.2020.119917

Sirojudin, G. A., \& Nazaruddin, I. (2014). Pengaruh modal intelektual dan pengungkapannya terhadap nilai dan kinerja perusahaan. Journal of $\begin{array}{llll}\text { Accounting and Investment, } & \text { 75(2), }\end{array}$ https://journal.umy.ac.id/index.php/ai/article/view/1328

Smith, M. (2019). Research methods in accounting. NY: SAGE Publications Limited.

Sofyani, H., \& Nazaruddin, I. (2019). The Effect of Implementation of Lecture Performance Measurement System and The Role Clarity of Lecturer Performance: A Study of Testing Mediation Effect. Jurnal Reviu Akuntansi dan Keuangan, 9(1), 34-45. https://doi.org/10.22219/jrak.v9i1.8246

Thaib, F. (2013). Value added intellectual capital (VAHU, VACA, STVA) pengaruhnya terhadap kinerja keuangan bank pemerintah periode 20072011. Jurnal EMBA: Jurnal Riset Ekonomi, Manajemen, Bisnis dan Akuntansi, 1(3), 151-159. https:// doi.org/10.35794/emba.v1i3.1951

Ulum, I. (2013). Model pengukuran kinerja intellectual capital dengan iB-VAIC di perbankan syariah. INFERENSI: Jurnal Penelitian Sosial Keagamaan, 7(1), 185-206. https:// doi.org/10.18326/infsl3.v7i1.185-206

Ulum, I. (2019). Intellectual capital framework perguruan tinggi di Indonesia berdasarkan instrumen akreditasi program studi (IAPS) 4.0. Jurnal Reviu Akuntansi Keuangan, 9(3), 309-318. https://doi.org/10.22219/jrak.v9i3.10227

Ulum, I., Harviana, R. R., Zubaidah, S., \& Jati, A. W. (2019). Intellectual capital disclosure and prospective student interest: An Indonesian perspectives. Cogent Business $\mathcal{E} \quad$ Management, 6(1), 1707041. https:/ / doi.org/10.1080/23311975.2019.1707041

Ulum, I., Malik, M., \& Sofyani, H. (2019). Analisis pengungkapan modal intelektual: Perbandingan antara universitas di Indonesia dan Malaysia. Jurnal Ekonomi dan Bisnis, 22(1), 163-182. https://doi.org/10.24914/jeb.v22i1.2343

$\mathrm{Xu}, \mathrm{J} .$, \& Li, J. (2020b). The interrelationship between intellectual capital and firm performance: evidence from China's manufacturing sector. Journal of Intellectual Capital. Vol. ahead-of-print No. ahead-of-print. https:/ / doi.org/10.1108/JIC-08-2019-0189

Xu, J., \& Liu, F. (2020a). The impact of intellectual capital on firm performance: a modified and extended VAIC model. Journal of Competitiveness, 12(1), 161176. https://www.cjournal.cz/files/361.pdf

Zikmund, W. G., Carr, J. C., \& Griffin, M. (2013). Business Research Methods. Boston: Cengage Learning. 